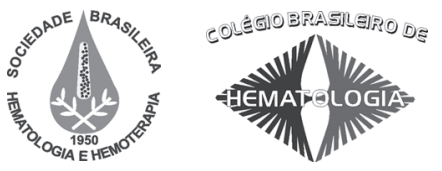

Artigo / Article

\title{
Prevalência de anemia em trabalhadores expostos ocupacionalmente ao chumbo
} Prevalence of anemia in workers with work-related exposure to lead

\author{
Renato Minozzo ${ }^{l}$ \\ Sandrine C. Wagner ${ }^{2}$ \\ Carolina H. Santos ${ }^{3}$ \\ Luiz I. Deimling ${ }^{4}$ \\ Renato S. Mello
}

\begin{abstract}
O chumbo é um dos elementos mais abundantes da natureza. Atualmente o chumbo é muito utilizado na manufatura de baterias, latão e bronze, radiadores, soldas, cabos, tintas, corantes, cerâmicas, munição, entre outros. A intoxicação do chumbo é chamada de saturnismo e está na maioria das vezes relacionada à atividade profissional. $O$ chumbo pode causar alterações neurológicas, hematológicas, renais, cardíacas e reprodutivas. O objetivo deste trabalho foi comparar os níveis sanguíneos de 53 trabalhadores expostos ocupacionalmente ao chumbo, com grupo controle não exposto a agentes químicos ou fisicos, avaliando dosagem de chumbo sérico, contagem de eritrócitos, hematócrito, dosagem de hemoglobina e idade. Com relação ao chumbo sérico, dentre o grupo exposto ocupacionalmente ao metal, 20,8\% dos trabalhadores apresentavam valores até $40 \mu \mathrm{g} / \mathrm{dL}, 35,8 \%$ obtiveram resultados entre $40 \mu \mathrm{g} / \mathrm{dL} e$ $60 \mu \mathrm{g} / \mathrm{dL}$, e 43,4\% apresentaram valores de chumbo sérico acima de $60 \mu \mathrm{g} / \mathrm{dL}$. Já no grupo controle, todas as amostras apresentaram valores abaixo de $40 \mu \mathrm{g} / \mathrm{dL}$ de chumbo sérico. Com relação à hemoglobina, 7,5\% dos trabalhadores do grupo controle e 34,0\% dos expostos apresentaram valores abaixo de $13 \mathrm{~g} / \mathrm{dL}$, com diferença estatisticamente significativa. Os resultados indicam que níveis elevados de chumbo estão relacionados com valores de hemoglobina abaixo dos índices de referência. Rev. Bras. Hematol. Hemoter. 2009;31(2):94-97.
\end{abstract}

Palavras-chave: Chumbo; exposição ocupacional; intoxicação por chumbo; anemia.

\section{Introdução}

O saturnismo é a intoxicação pelo chumbo e está na maioria das vezes relacionado à atividade profissional. A exposição ocupacional ao chumbo ocorre principalmente na produção de baterias e em outras atividades como fundição, solda, fabricação de cerâmica, uso de tintas que contêm chumbo, mineração, entre outras. ${ }^{1}$ Esta intoxicação tem diminuído em países desenvolvidos, porém, em países em desenvolvimento continua a incidência de várias anormalidades associadas ao metal. ${ }^{2}$

O chumbo pode ser considerado um contaminante ambiental bastante comum na Grande Porto Alegre, incluin- do o Vale do Rio dos Sinos, no estado do Rio Grande do Sul, Brasil. ${ }^{3}$ Este metal pode penetrar o organismo através da inalação (ar atmosférico), ingestão (água, alimentos e solo contaminados) e por via dérmica. As principais manifestações clínicas pela exposição ao chumbo são gastrintestinais, renais, reprodutivas, hematológicas, neurológicas e carcinogênicas. ${ }^{4}$ Além disso, estudos demonstram que essa exposição está associada a danos cromossômicos. ${ }^{3,5,6}$ No Brasil, uma das principais formas de exposição e contaminação pelo chumbo é a atividade de reciclagem de baterias automotivas. Na maioria das vezes, o processo se dá em pequenas indústrias, sem a devida proteção aos trabalhadores. ${ }^{7}$

\footnotetext{
${ }^{1}$ Biomédico. Coordenador do Curso de Biomedicina - Feevale - Nova Hamburgo-RS.

${ }^{2}$ Professora Adjunta. Hematologia Clínica - Feevale - Nova Hamburgo-RS.

${ }^{3}$ Farmacêutica-Bioquímica.

${ }^{4}$ Técnico do Laboratório de Mutagênese, Ulbra - Canoas-RS.

${ }^{5}$ Professor. Genética Toxicológica Ocupacional e Ambiental, Ulbra - Canoas-RS.
}

Correspondência: Renato Minozzo

Rua Brasil 1169, sala 503 - Centro

92310-150 - Canoas-RS

Tel.: (55 51)3466-4786

E-mail:minozzo@feevale.br

Doi: 10.1590/S1516-84842009005000018 
O chumbo inibe a capacidade do organismo de produzir hemoglobina, afetando várias reações enzimáticas, críticas para a síntese do heme. A atividade de três enzimas (5-aminolevulinato desidratase, coproporfirinogênio oxidase e ferroquelatase) é inibida pelo chumbo. Isso enfraquece a síntese de heme e diminui a síntese de 5-aminolevulinato sintetase, enzima inicial e limitante da taxa da biossíntese do heme, e da coproporfirinogênio descarboxilase. ${ }^{8,9}$

Os limites de tolerância biológicos propostos para a intoxicação ocupacional pelo metal variam de legislação de acordo com cada país. No Brasil, segundo a NR-7, o valor de referência da normalidade (valor encontrado em população não exposta), para o chumbo no sangue é de $40 \mu \mathrm{g} / \mathrm{dL}$ e o Índice Máximo Biológico Permitido (IMBP) é de $60 \mu \mathrm{g} / \mathrm{dL}$. Quando este valor é ultrapassado indica exposição excessiva do trabalhador ao metal, causando possíveis riscos a saúde. A American Conference of Government Industrial Hygienists dos Estados Unidos, apresenta como índice biológico de exposição o valor de $30 \mu \mathrm{g} / \mathrm{dL} .^{10}$

Frente às informações acima descritas sobre a influência do chumbo na hematopoese, o presente trabalho teve como objetivo avaliar e comparar os índices hematimétricos dos trabalhadores expostos ocupacionalmente ao chumbo e o grupo controle.

\section{Casuística e Método}

O estudo foi realizado em 53 homens, com idades entre 18 e 55 anos, que trabalham na indústria e reciclagem de baterias automotivas de 11 microempresas na grande Porto Alegre e Vale do Rio do Sinos, no estado do Rio Grande do Sul, e que concordaram em participar do presente estudo. O grupo controle foi constituído de 53 indivíduos sadios, do sexo masculino, com idades entre 18 e 55 anos, que não apresentaram história de exposição a agentes químicos, físicos ou biológicos, nível socioeconômico semelhante ao dos operários e com residência na mesma região geográfica. A concentração de chumbo e determinação dos índices hematimétricos foi realizada a partir da coleta de sangue em tubos contendo heparina e EDTA, respectivamente. As amostras foram coletadas e armazenadas em temperatura refrigerada até o momento das análises $\left(2^{\circ} \mathrm{C}\right.$ a $\left.8^{\circ} \mathrm{C}\right)$ após leitura e assinatura do Termo de Consentimento Livre e Esclarecido (TCLE).

Os níveis de chumbo no sangue foram determinados pelo método de espectrofotometria de absorção atômica, utilizando equipamento Perkin Elmer, modelo 4110 ZeemanSimaa. ${ }^{11}$ Os índices hematimétricos foram determinados em contador automatizado de células (Advia 60- Bayer) seguindo o protocolo do fabricante. A análise estatística dos dados foi realizada através do teste não-paramétrico (teste de significância de Mann Whitney) usando o programa SPSS.

O estudo foi realizado após aprovação pelo Comitê de Ética em Pesquisa da Universidade Luterana do Brasil (Ulbra) e desenvolvido obedecendo integralmente os princípios éti- cos estabelecidos na Resolução 196/96 do Conselho Nacional de Saúde.

\section{Resultados}

A Tabela 1 apresenta a média de idade, tempo de exposição ao chumbo, número de eritrócitos, hematócrito, valores de hemoglobina, número de leucócitos e concentração de chumbo nos indivíduos analisados.

A Figura 1 apresenta a distribuição dos trabalhadores expostos ao chumbo pelos níveis sanguíneos do metal no sangue, onde $20,8 \%$ estão dentro do valor de referência e os demais estão acima deste valor, destacando que $43,4 \%$ estão acima do Índice Biológico Máximo Permitido (IBMP).

A Figura 2 apresenta o número de indivíduos dos grupos exposto e controle com anemia $(\mathrm{Hb}<13 \mathrm{~g} / \mathrm{dL})$.

Tabela 1. Idade, tempo de exposição, valores hematológicos e concentração de chumbo (Controles $X$ Expostos)

\begin{tabular}{|c|c|c|c|c|}
\hline & \multicolumn{4}{|c|}{ Teste de Mann-Whitney } \\
\hline & Controle & Expostos & Valores de Z & $\begin{array}{c}\text { Valores de } \\
P\end{array}$ \\
\hline $\begin{array}{l}\text { Números de } \\
\text { indivíduos }\end{array}$ & 53 & 53 & & \\
\hline Idade (anos) & $33,1 \pm 11,7$ & $36,0 \pm 10,5$ & $-1,616$ & 0,106 \\
\hline $\begin{array}{l}\text { Tempo trabalho } \\
\text { (anos) }\end{array}$ & - & $9,8 \pm 11,1$ & - & - \\
\hline $\begin{array}{l}\text { Eritrócitos } \\
(x 10 \% \mu L)\end{array}$ & $5,00 \pm 0,37$ & $4,87 \pm 0,49$ & $-1,062$ & 0,288 \\
\hline $\begin{array}{l}\text { Hematócrito } \\
(\%)\end{array}$ & $43,6 \pm 2,9$ & $42,5 \pm 4,1$ & $-1,551$ & 0,121 \\
\hline $\begin{array}{l}\text { Hemoglobina } \\
(\mu g / d L)\end{array}$ & $14,5 \pm 1,0$ & $13,7 \pm 1,4$ & $-3,205$ & $0,001^{*}$ \\
\hline $\begin{array}{l}\text { Leucócitos } \\
\left(\times 10^{3} / \mu \mathrm{L}\right)\end{array}$ & $6,9 \pm 1,8$ & $7,8 \pm 2,8$ & $-1,763$ & 0,078 \\
\hline $\begin{array}{l}\text { Chumbo } \\
(\mu \mathrm{g} / \mathrm{dL})\end{array}$ & $2,44 \pm 1,15$ & $59,43 \pm 28,34$ & $-8,877$ & $<0,001^{*}$ \\
\hline
\end{tabular}

* Com diferença estatística

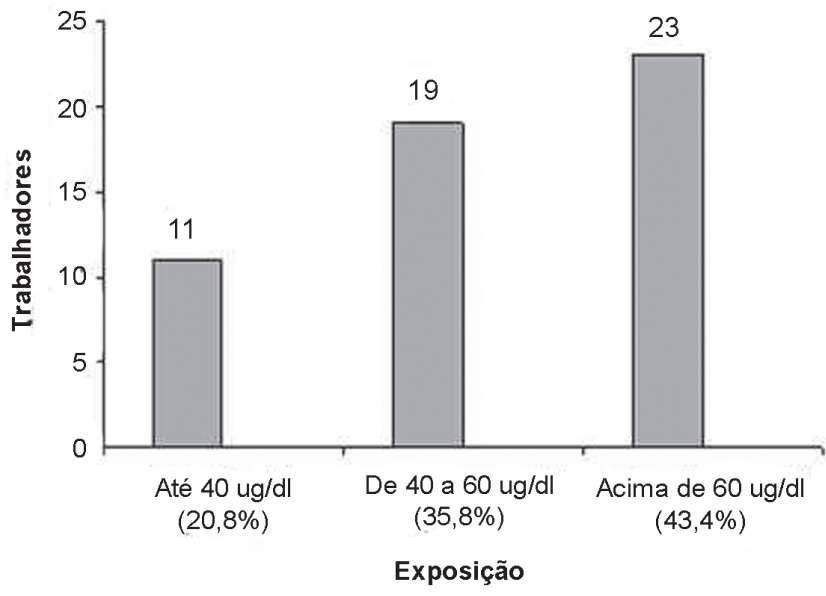

Figura 1. Distribuição de trabalhadores por valores de chumbo no sangue de acordo com o IBMP 


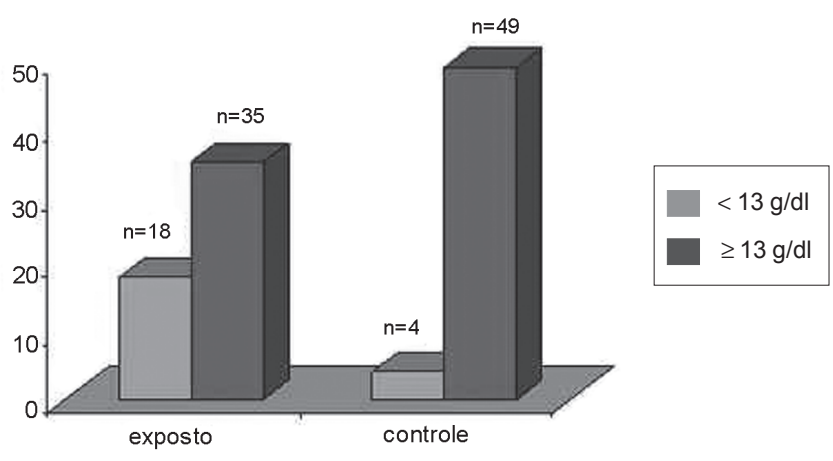

Figura 2. Número de indivíduos dos grupos exposto e controle com anemia $(\mathrm{Hb}<13 \mathrm{~g} / \mathrm{dL})$

\section{Discussão}

O chumbo não apresenta nenhuma função fisiológica conhecida sobre o organismo de seres humanos e animais, mas pode induzir vários tipos de toxicidade. Segundo o Ministério da Saúde, no Brasil não existem registros confiáveis do número de indivíduos expostos ocupacional e ambientalmente ao metal, embora estudos venham apontando grupos de trabalhadores intoxicados, principalmente entre os envolvidos na produção, reforma e reciclagem de baterias automotivas. Da mesma maneira, a produção de baterias chumbo-ácido representa o segmento industrial responsável pelo maior consumo de chumbo nos países em desenvolvimento, pelo fato da tecnologia ser bastante simples e a possibilidade da realização em pequena escala. Devido às condições de trabalho e às propriedades tóxicas do chumbo, muitos trabalhadores deste setor estão frequentemente expostos a elevadas concentrações do metal. Para realizar o diagnóstico de intoxicação por chumbo, é analisado um conjunto de informações sobre o trabalhador, tais como evidências de exposição ocupacional ao metal, evidências laboratoriais de exposição e efeitos biológicos associados à exposição ao chumbo, sinais e sintomas compatíveis com o saturnismo. ${ }^{12}$

O presente estudo apresentou uma diferença significativa na dosagem de chumbo sérico entre os grupos analisados. Todos os trabalhadores do grupo controle apresentaram valores dentro dos limites normais estabelecidos pela NR-7. A dosagem no grupo exposto ocupacionalmente indicou que apenas $20,8 \%$ dos trabalhadores apresentavam níveis normais do metal (até $40 \mu \mathrm{g} / \mathrm{dL}$ ), 35,8\% dos trabalhadores obtiveram resultados entre o nível normal e o IBMP $(40 \mu \mathrm{g} / \mathrm{dL}-60 \mu \mathrm{g} / \mathrm{dL})$ e $43,4 \%$ apresentaram valores de chumbo sérico maior que o IBMP. Estes resultados se devem não só à exposição dos indivíduos ao ambiente contaminado pelo chumbo, mas também aos hábitos dos mesmos. Estudos mostram que a falta de higiene no local de trabalho é um dos potencializadores para a intoxicação pelo chumbo. Alguns trabalhadores costumam fazer suas refeições ou fumar em áreas contaminadas, aumentando a ingestão do metal. O chumbo, quando ingerido junto com alimentos, pode aumentar de $10 \%$ a $15 \%$ a absorção. ${ }^{10}$ Pesquisas realizadas em indústrias de baterias chumbo-ácido mostram que há diferença significativa entre os níveis de chumbo sérico nos países desenvolvidos, como os Estados Unidos, no qual apenas 6\% apresentam concentrações acima do IMBP, comparados com países como a Coréia, na qual 38\% dos trabalhadores estão acima do IMBP. ${ }^{13} \mathrm{O}$ uso de equipamento de proteção individual (EPI) e o cuidado com a higiene própria, como lavar as mãos, o rosto e os cabelos no fim da jornada devem ser hábitos constantes dos trabalhadores e contribuem para a menor absorção de chumbo. ${ }^{14}$ Dietas deficientes em ferro, cálcio e zinco também podem contribuir para uma maior absorção do metal no trato gastrointestinal. ${ }^{10}$

Além do chumbo sérico, a dosagem de hemoglobina também foi significativamente diferente entre os grupos. Apenas $10 \%$ dos trabalhadores do grupo controle apresentavam hemoglobina abaixo dos valores de referência $(<13 \mathrm{~g} / \mathrm{dL})$. Já no grupo exposto, $37,5 \%$ dos trabalhadores mostravam o mesmo resultado $(\mathrm{P}<0,001)$. Justifica-se $\mathrm{o}$ achado destes resultados porque altos níveis de chumbo estão relacionados à diminuição da síntese do grupo heme através da intoxicação pelo chumbo, onde ocorre em várias etapas, como a inibição das enzimas ácido $\mu$-amino levulínico (ALA) sintase, $\delta$-aminolevulínico desidratase (ALA-D), coproporfirinogênio descarboxilase e ferroquelatase, e pela diminuição do tempo de meia-vida dos eritrócitos, mais evidente em exposição aguda ao chumbo. ${ }^{9}{ }^{15} \mathrm{O}$ polimorfismo genético também pode causar uma maior suscetibilidade à intoxicação ao chumbo. Estudos recentes sugerem que este quadro ocorre, além da alteração no receptor da vitamina $\mathrm{D}$, no gene que codifica a ALA-D. A alteração do gene $\mathrm{D}$ (alelos $\mathrm{D}^{1}$ e $\mathrm{D}^{2}$ ) pode contribuir para uma sensibilidade individual à diminuição da síntese do grupo heme. ${ }^{16}$ Não houve uma diferença significativa entre o número de hemácias, hematócrito e número total de leucócitos.

As medidas preventivas da intoxicação pelo chumbo estão no plano da prevenção primária, que visa diminuir ou eliminar a exposição ocupacional. Deve-se evitar a exposição através do uso de EPIs, principalmente quando não estiverem disponíveis os equipamentos de proteção coletiva (EPCs), além de boas práticas nos locais de trabalho. A NR-7 cita que os trabalhadores que apresentam resultados entre $40 \mu \mathrm{g} / \mathrm{dL}-60 \mu \mathrm{g} / \mathrm{dL}$ não representariam doença ou outra disfunção orgânica e poderiam continuar as atividades normalmente.

De acordo com o Ministério da Saúde, um trabalhador com sintomatologia de doença ocupacional aponta a existência de outros casos dentro do local e necessidade de melhoria no ambiente de trabalho. Toda intoxicação ocupacional por chumbo é passível de notificação compulsória pelo SUS, segundo parâmetros da Portaria GM/MS/777, de 28 de abril de 2004, e deve ser comunicada à Previdência 
social, por meio de abertura de Comunicação de Acidente de Trabalho (CAT). ${ }^{17}$

Este estudo demonstra índices elevados de chumbo em um grupo de indivíduos expostos diretamente a este metal. Além disso, esses indivíduos apresentam alta frequência de anemia, considerada um dano hematológico bastante comum a esta exposição, sendo evidente quando existem níveis elevados de chumbo por períodos prolongados.

A melhora da ventilação no local, prevenção de dispersão de poeiras, monitoramento do chumbo no ambiente e o uso correto dos EPI's são medidas preventivas à exposição ao chumbo e que devem ser implementadas para minimizar a intoxicação dos funcionários.

Cabe ressaltar que a região da grande Porto Alegre e Vale do Rio dos Sinos apresenta uma população de aproximadamente 3 milhões de habitantes, sendo considerada importante polo industrial da Região Sul do Brasil. Com relação à reciclagem de baterias automotivas, não existem registros confiáveis do número exato, uma vez que grande parte delas não se encontra legalmente estabelecida e a mão de obra é constituída, muitas vezes, por indivíduos da própria família, fato este constatado durante a realização deste trabalho.

\footnotetext{
Abstract

Lead is one of the most abundant elements in nature. Currently, it is widely used in the manufacture of batteries, brass and bronze, radiators, solders, cables, paints and dyes, ceramics, and ammunition, among other things. Lead intoxication is called saturnism and is most often related to professional activities. Lead can cause neurological, hematological, renal, cardiac and reproductive disorders. The aim of this study was to compare blood parameters of 53 workers with work-related exposure to lead with a control group of individuals not exposed to chemical or physical agents. Serum lead levels, red blood cell count, hematocrit and hemoglobin levels and age were evaluated. In respect to serum lead levels, of the group with work-related exposure to the metal, $20.8 \%$ of the workers had values of up to $40 \mu \mathrm{g} / \mathrm{dL}, 35.8 \%$ presented with values between $40 \mu \mathrm{g} / \mathrm{dL}$ and $60 \mu \mathrm{g} / \mathrm{dL}$ and $43.4 \%$ above $60 \mu \mathrm{g} / \mathrm{dL}$. In the control group, all samples presented values below $40 \mu \mathrm{g} / \mathrm{dL}$. A statistically significant difference was observed between the groups, as $7.5 \%$ of workers in the control group and $34.0 \%$ of workers with occupational exposure presented with hemoglobin levels lower than $13 \mathrm{~g} / \mathrm{dL}$. These results indicate that high levels of lead are related to hemoglobin values below the normal range. Rev. Bras. Hematol. Hemoter. 2009;31(2):94-97.
}

Key words: Lead; work-related exposure; lead intoxication; anemia.

\section{Referências Bibliográficas}

1. Dona A, Dourakis S, Papadimitropoulos B, Maravelias C, Koutselinis A. Flour contamination as a source of lead intoxication. J Toxicol Clin Toxicol. 1999;37(1):109-12.

2. Spínola AG, Fernícola NA, Mendes R. Intoxicação profissional por chumbo. In: Mendes R (Ed.) Medicina do Trabalho - Doenças Profissionais. São Paulo: Sarvier, 1980. p.437-460.

3. Minozzo R, Deimling LI, Gigante LP, Santos-Mello R. Micronuclei in peripheral blood lymphocytes of workers exposed to lead. Mutat Res. 2004;565(1):53-60.

4. Mavropoulos E. A Hidroxiapatita como removedora de chumbo. Tese de mestrado em Saúde, Escola Nacional de Saúde Pública, Fiocruz. Rio de Janeiro, 1999.

5. Palus J, Rydzynski K, Dziubaltowska E, Wyszynska K, Natarajan AT, Nilsson R. Genotoxic effects of occupational exposure to lead and cadmium. Mutat Res. 2003;540(1):19-28.

6. Chen Z, Lou J, Chen S, Zheng W, Wu W, Jin L, et al. Evaluating the genotoxic effects of workers exposed to lead using micronucleus assay, comet assay and TCR gene mutation test. Toxicology. 2006; 223(3):219-26.

7. Paoliello MM, De Capitani EM. Occupational and environmental human lead exposure in Brazil. Environ Res. 2007;103(2):288-97.

8. Saryan LA, Zenz C. Lead and its compounds. In: Zenz C, Dickerson OB, Horvath EP Jr (Eds). Occupational Medicine. $3^{\mathrm{a}}$ ed. St. Louis: Mosby, 1994. p.506-541.

9. Moreira FR, Moreira JC. Os efeitos do chumbo sobre o organismo humano e seu significado para a saúde. Rev Panam Salud Publica. 2004;15(2):119-29.

10. Agency for Toxic Substances and Disease Registry. Toxicological profile for lead. 2007. Public Health Service- U.S. Department of Health and Human Services, Atlanta. Disponível em: http:// atsdr.cdc.gov/toxprofiles/tp13.pdf. Acesso em janeiro/2009.

11. Bosnak CP, Bradshaw D, Hergenreder R, Kingston K. Graphite furnace analysis of $\mathrm{Pb}$ in blood using continuum source background correction. Atomic Spectroscopy. 1993;14(3):80-2.

12. [MS] Ministério da Saúde. Secretaria de Atenção à Saúde. Atenção à saúde dos trabalhadores espostos ao chumbo metálico. Série A. Normas e Manuais Técnicos. Editora MS. Brasília, 2006.

13. Matte TD, Figueroa JP, Burr G, Flesch JP, Keenlyside RA, Baker EL. Lead exposure among lead-acid battery workers in Jamaica. Am J Ind Med. 1989;16(2):167-77.

14. Chuang HY, Lee ML, Chao KY, Wang JD, Hu H. Relationship of blood lead levels to personal hygiene habits in lead battery workers: Taiwan, 1991-1997. Am J Ind Med. 1999;35(6):595-603.

15. Henretig MF. Lead. In Goldfrank LR, Flomenbaum N, Hoffman R, Lewin N, Howland M, Lewis N. Goldfrank's Toxicology Emergencies. McGraw-Hill, 7th ed, 2002.

16. Onalaja AO, Claudio L. Genetic susceptibility to lead poisoning. Environ Health Perspect. 2000;108 Suppl 1:23-8.

17. [MS]. Ministério da Saúde. Portaria n. $777 /$ GM, de 28 de abril de 2004. Dispõe sobre os procedimentos técnicos para a notificação compulsória de agravos à saúde do trabalhador em serviço sentinela específica, no Sistema Único de Saúde (SUS). Diário Oficial da União, Poder Executivo, Brasília, DF, nº 81, 29 abr. 2004.1: 37-38.

Avaliação: Editor e dois revisores externos

Conflito de interesse: não declarado

Recebido: 27/10/2008

Aceito após modificações: 15/01/2009 